
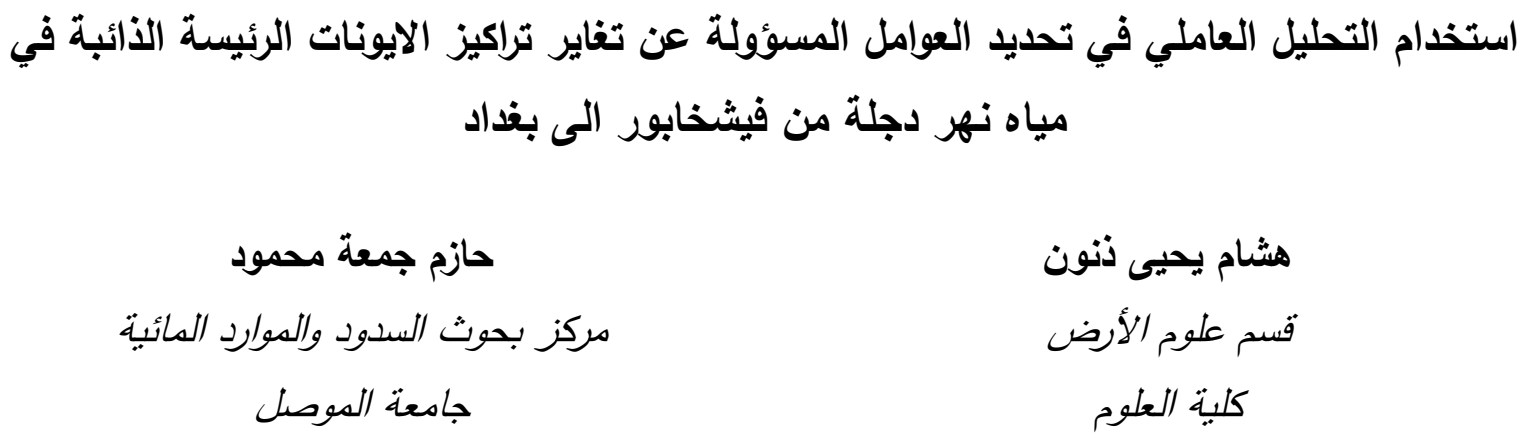

$$
\text { هشام يحيى ذنون علوم الأرض }
$$

$$
\text { (تاريخ الاستلام 2013/3/12 ، تاريخ القبول 2013/9/1) }
$$

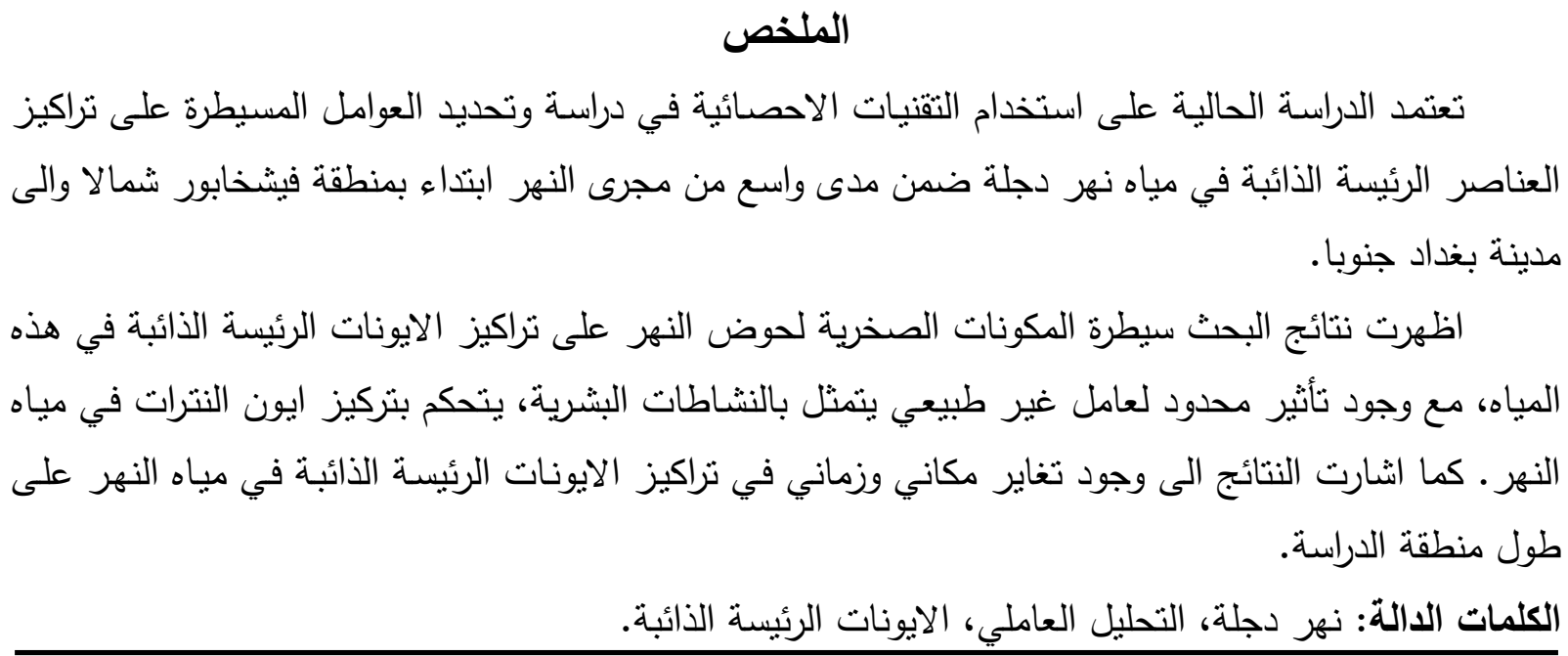

\title{
The Use of Factor Analysis in Defining Factors Responsible for the Variation of the Concentrations of Dissolved Major Ions in Tigris River Water from Fishkabur to Baghdad
}

\author{
Hisham Yahya Dhannoun \\ Dept. of Geology \\ College of Science \\ Mosul University
}

\author{
Hazim Jumaa Mahmood \\ Dams and Water Resources \\ Research Center \\ Mosul University
}

\begin{abstract}
The current study is based on the use of statistical techniques to study and identify factors controlling the concentrations of dissolved major elements in Tigris River water within a wide range of the river course, starting from Fishkabur region in the north to Baghdad city in the south.

The Results show that the rock compositions of the river basin mainly control the concentrations of the dissolved major ions in the river water with limited effect of anthropogenic factor, represented by human activities, that controls the nitrate ion concentration. The results also indicate the presence of spatial and temporal variations in the dissolved major ions concentrations, along the study area.
\end{abstract}


Keywords: Tigris River, Factor Analysis, Dissolved Major Ions.

\section{المقدمة}

تشير البحوث المنشورة عن كيمياء المياه الى ان التركيب الكيميائي لمياه الأنهار يتغاير بشكل واضح مـع تغاير المكان والزمان، وبات من المعروف ان هناك عوامل كثيرة تتحكم بكيمياء الانهار • وان من اهم تلك العوامل لهل

جيولوجية حوض النهر: اذ أجرى (Souza and Tundisi, 2000) مقارنة بين نهر Jau (مواد الحوض تتألف من صـخور البازلت والتربـة البازلتيـة) ونهر Jacare-Guacu (بمواد حوض تتألف من صـور الحجر الرملي النهري والبازلت والترسبات الحديثة) الواقعين في البرازيل، وقد وجدا ان تراكيز الايونات الرئيسة والتغاير فيها يكون

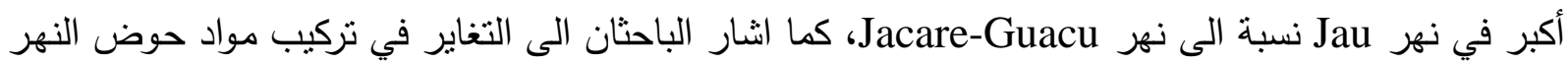
كأحد الاسباب الرئيسة للتغاير في التركيب الكيميائي بين مياه النهرين. كما تبين في دراسة اخرى اجريت على نهر Kalix النسبة Ca/Mg تزداد في مياه النهر خـل تساقط الامطار على منـاطق التغذيـة الجبلية المتكونـة من صخور الكربونات وصخور الثست، بينما تزداد النسبة Si/Mg خـلال فترات ذوبان النلوج المغطية لمناطق نتكون من صخور الكرانيت بشكل اساسي. وقد اشار (Chakrapani, 2005) الى مساهمة عدد من العوامل في التأثير على كيميائية نهر الكانج (Ganga River) في الهند وان التعرية الصخرية تكون هي العامل الاقوى، كما حاول حساب مساهمة كل من صخور الكربونات والصخور السليكاتية في تزويد النهر بالعناصر الكيميائية، ووجد ان لنوعية المعادن المكونة للصخور دورا مهما في تزويد النهر بالحمل الذائب.

المناخ والطبوغرافيةة: وجد (Sabater et al., 1990) ان الخصائص الطبوغرافية لحوض نهر Ter في اسبانبا، تلعب دورا اساسيا في زيادة ملوحة مياه النهر باتجاه المصب، وهذا يحدث جنبا الى جنب مع تأثنر ليثولوجية الحوض ونوعية التربة ونوعية استخدامات الارض. اما كل من (Chakrapani, 2005) و ( Pittaluga and فقد اشـاروا الى دور المناخ في التأثنر على تراكيز العناصر في مياه كل من نهر الكانج ونهر كاستانو (Ganga River) بشكل كبير من تراكيز العناصر في هذه الانهار نتيجة التخفيف بمياه الامطار.

الغطاء التباتي ونثـاطات الاحياء المائية: اشـار (Scobee and Prophet, 1967) الى ان تراكيز النترات والفوسفات في نهر Cottonwood في الولايات المتحدة الامريكية يكون مسبطرا عليها من قبل النباتات المائية التي تستخدمها في عملية التغذية، الامر الذي ادى الى عدم تغاير تراكيزها في مياه النهر اعلى وأسفل سد ماريون على الرغم من التغاير في المكونات الصخرية. اما (Anderson et al., 1968) فقد وجدوا ان هنالك تغايرا واضحا في تراكيز الاوكسجين وثاني اوكسيد الكاربون، فضلا عن تغاير طفيف في بعض الايونات الرئيسة خلال اليوم الواحد في مياه نهر Patuxent في الولايات المتحدة الامريكية، حيث وجدوا ان تراكيز الاوكسجين تزداد خلا النهار وتقل خلال الليل، بينما كان سلوك CO2 على العكس من ذلك. واستتتجوا ان سبب هذا التغاير هو 
الفعاليات الحياتية للنباتات المائية. امـا (Ingri et al., 2005) فقد اثناروا الى ان الغابات الموجودة في حوض نهر Kalix لها دور واضح في التأثير على كيميائية النهر.

العوامـل غير الطبيعيـة (نشـاطات الانسـان): وجد (Scobee and Prophet, 1967) ان الاراضـي الزراعيـة والفعاليات المدنية على نهر Cottonwood اعلى سد ماريون (Marion Dam) تتسبب في زيادة تراكيز بعض الايونـات أسـفل الســ نتيجـة لانتتــار الاراضـي الزراعيـة والتجمعـات السـكنية حـول خـزان الســــ بينمـا اثــار (Konhauser et al., 1995) دراستهم لثلاتة انهار في هذه الولاية، وقد تبين لهم عن طريق اختيار محطات لجمع نماذج المياه اعلى وأسفل المناطق الصناعية ان النشاط الصناعي في هذه المنطقة يؤثر بشكل سلبي في تلوث مياه الانهار ، وبشكل خاص تلك الانهار التي تمتاز بتصريف منخفض. تطرق (Adekola and Eletta, 2007) الى تلوث الرسوبيات النهرية بشكل واضح لنهر Asa في نيجيريا بتأثنر مصادر غير طبيعية (Anthropogenic source). كما اشار (Kucuksezgin et al., 2008) نهر Gediz في تركيا نتيجة لمطروحات النشاطات البشرية التي تطرح في النهر • درس ( Moskovchenko et Vيدروكيميائية نهر Vatinsky Egan (al., 2009 بتطور حقول النفط في هذه المنطقة، وتبين ان الملوحة في مياه النهر تزداد بشكل مفاجئ خلال عبور النهر لحقل Samotlor بالعناصر التقيلة نتيجة لطرح المياه الصناعية والزراعيـة الى النهر ، وتبين ان مياه النهر تعد ملوثة بالكادميوم والنيكل حسب المواصفات القياسية العالمية. وجد (Sundaray et al., 2012) في دراسـة مفصلة عن نهر Mahanadi في الهند ان عددا من العناصر الثقيلة في مياه النهر تكون اعلى من المعدل العالمي للأنهار، وقد اشـارت الانماط الخاصـة بهذه العناصر الى احتمالية وجود مصدر غير طبيعي يزود مياه النهر بهذه العناصر ومن المرجح ان يكون نتيجة لعمليات التسميد والمبيدات المستعملة في الاراضي الزراعية، وهذا ما ادى الى ارتفاع التراكيز خلا تساقط الامطار على هذه الاراضي نتيجة لعمليات الغسل ونقل العناصر الى مياه النهر . أما الوفرة النسبية للعناصر في مياه الأنهار فتعتمد على وفرة العنصر المعين في القترة الأرضية وقابلية العنصر على الحركة والانتقال إلى البيئة المائية (Gaillardet et al., 2004). ولما كانت تراكيز العناصر الكيميائية في مياه الانهار تتغاير مـع الزمان والمكان، لذا يمثل البحث الحالي

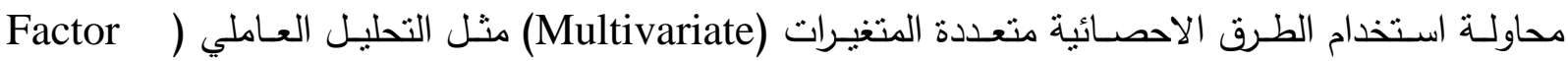
(Analysis والتحليـل العنقـودي (Cluster Analysis) التـي تعـد مـن الطرائق الثـائعة في الدراسـات الهيدروكيميائية (Bakac and Kumru, 2001; Chen et al., 2007)، وذلك لبيان التغاير في تراكيز الايونات الرئيسة من فيشخابور الى بغداد. وهذا ما تفتقر الية العديد من الدراسات عن هيدروكيميائية المياه. ومثال ذلك نهر دجلة الذي يعد أهم مورد من موارد المياه في العراق. ينبع نهر دجلة من عدة منابع في المرتفعات الواقعة في جنوب شرق تركيا إلى الجنوب الثرقي من منابع نهر الفرات. ويدخل النهر الأراضي العراقية عند قرية فيشخابور، وبستمر في جريانه باتجاه الجنوب الثرقي إلى أن يصب في بحيرة سد الموصل بعد حوالي 42 كم من دخول النهر إلى الأراضي العراقية. يستمر النهر بعد سد 
الموصل بالجريان في أراضي متموجة إلى مضيق الفتحة الذي يفصل مرتفعات حمرين عن مرتفعات مكحول. ويكون مجرى النهر في هذا الجزء محاطا بسهل ضيق ويتسع قليلا بين الفتحة وبلد مـع ظهور الحافات الصخرية على مجراه أحيانـا، خاصـة في مدينة سامراء. يجري النهر بعد سـامراء وبلد في السهل الرسوبي وبيتاز بكثرة تعرجاته وبطء جريانه بالأخص في جزئه الواقع بين مدينتي بغداد والكوت وذللك بسبب قلة انحدار الأرض. ويغطي حوض نهر دجلة مع روافده معظم الأراضي الواقعة في شمالي وشرقي العراق (الثكل 1). على الرغم من اجراء العديد من الدراسات المختلفة على نهر دجلة، الا ان المعلومات عن الهيدروكيميائية،

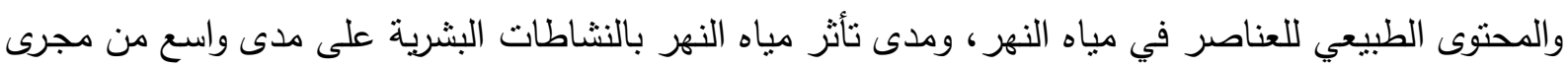
النهر، لاتزال غير متكاملة وغير دقيقة. وبشكل خاص فان الباحثين لم يلاحظا وجود دراسات احصائية معتبرة عن علاقات العناصر الذائبة، والعوامل المؤثرة على هيدروكيميائية مياه النهر ـ لذلك كان هدف البحث الحالي استخدام التحليل الإحصائي لبيان العوامل المؤثرة على هيدروكيميائية العناصر الرئيسة الذائبة في مياه نهر دجلة.

\section{جيولوجية مجرى نهر دجلة:}

Nappe ) يقطع نهر دجلة اثثاء جريانه في جنوبي تركيا منطقة معقدة جدا من الصخور النارية والمتحولة (Nicoll, 2009)(zone ) فضلا عن قطعه لمكونات الحقبة الجيولوجية المتوسطة (Mesozoic) من التراياسي هني والجوراسـي والكريتاسـي. وعند دخول النهر الأراضـي العراقيـة يقطع ترسبات المولاس والمتمتلـة بتكوين مقداديـة (البلايوسين) ثم تكوين انجانـة (المايوسـين الأعلى) ثم يقطع النهر بعـ هذه الترسبات ترسبات تكوين فتحـة (المايوسين الأوسط) ويستمر على هذا النحو الى ناحية وانة. ثم يقطع الترسبات النهرية الحديثة ابتداء من وانة فبادوش فالموصل وحتى محل التقاء النهر بالزاب الأعلى جنوب الموصل. ثم تعود طبقات تكوين فتحة بالظهور في مجرى النهر ثم يعود النهر ليقطع الترسبات الحديثة (المرهج، 1979)، يستمر النهر بالسير خلال الترسبات النهريـة الحديثة والتي تظهر على طول المجرى خـل مسير النهر في منطقة القيارة والى قريـة المسحك أسفل مصب الزاب الأسفل في نهر دجلة بحوالي 4 كم. ثم تظهر مكاشف تكويني فتحة وانجانة في منطقة الفتحة. ثم يستمر النهر ليقطع تكوين مقدادية الذي يمتد على جانبي النهر من منطقة الفتحة وحتى شمال مدينة بلد (5 كم). ثم تظهر بعد ذلك الترسبات النهرية الحديثة التي يقطعها النهر حتى مدينة بغداد (البياتي، 1980). 


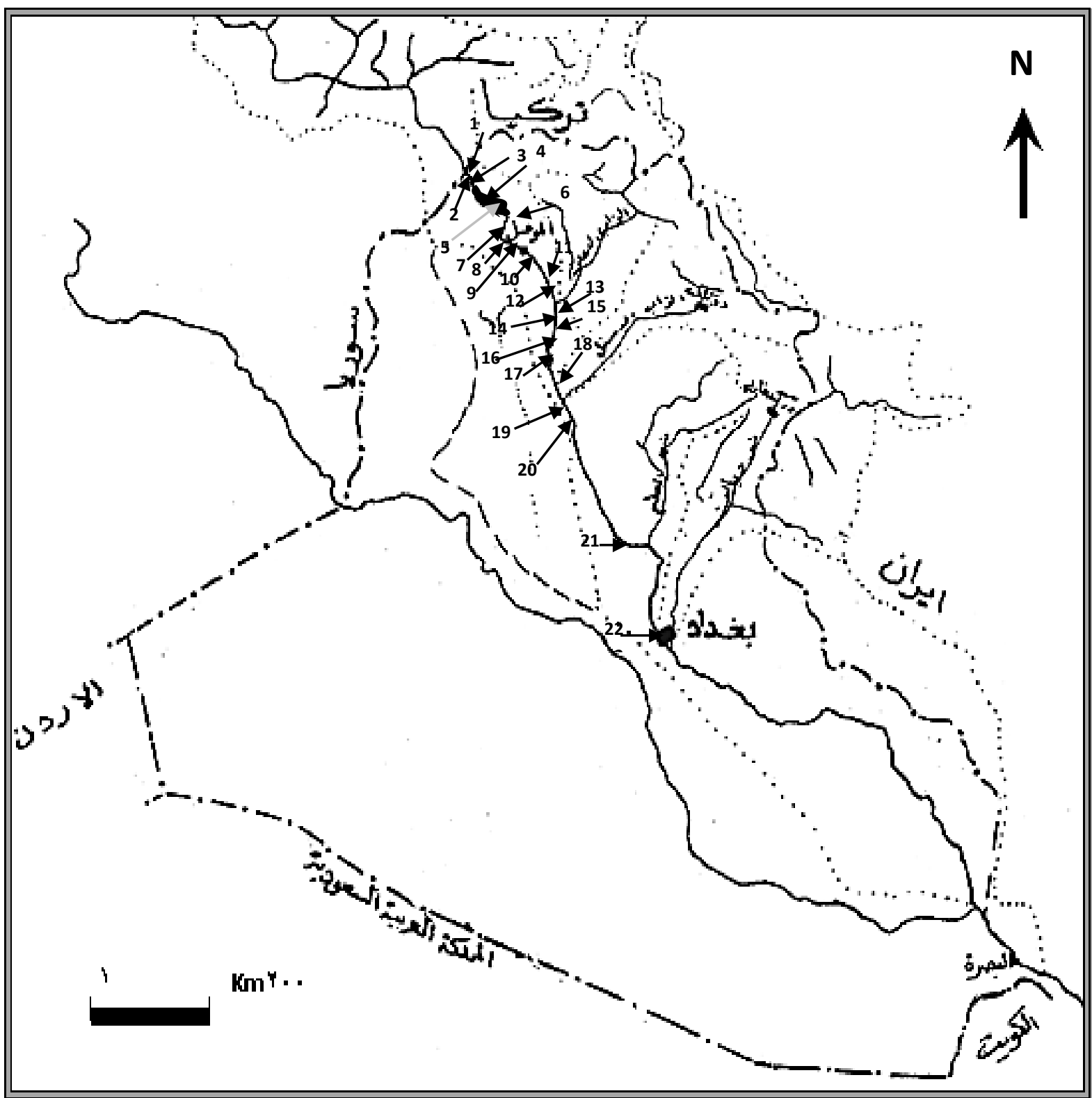

الثكل 1: خارطة حوض نهر دجلة وروافهه (الخفاجي 1985) موضح عليه مقاطع الندجة (1-22)

رغم أن المجرى الرئيس لنهر دجلة يمر خلال عدد قليل من التكوينات، إلا ان حوض النهر داخل العراق والمتنتل بروافد وأحواض الروافد المغذية للنهر تغطي معظم الأراضي في شمالي وشرقي العراق (شكل 1)، والتي

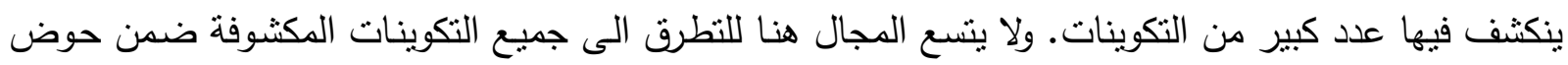
نهر دجلة. والذي يضم جميع النكوينات المنكثفة في شمالي وشمال غربي العراق. وبإمكان القارئ العودة الى لى

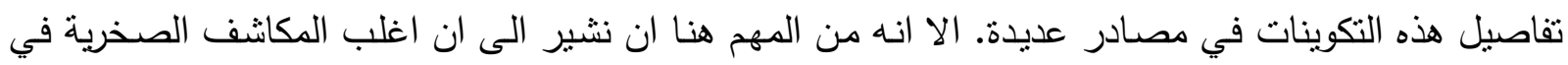
حوض نهر دجلة داخل العراق تتألف بشكل رئيس من صخور الكربونات والمتبخرات والمارل والصخور الطينية

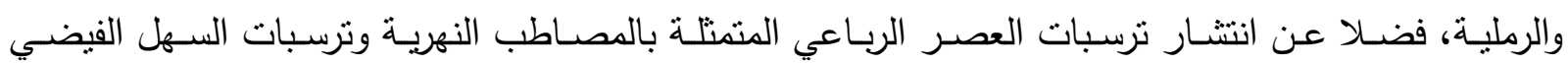

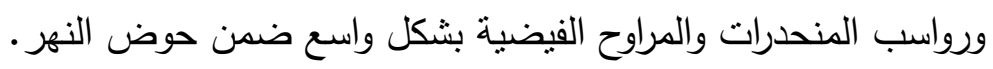




\section{طرائق التحليل والنتائج}

تضمنت بيانات البحث نتائج تحليل العناصر الرئيسة في 34 نموذجا من مياه نهر دجلة تم جمعها من وسط النهر موزعة على 22 موقعا ضمن منطقة الدراسة الممتدة من بداية دخول النهر الى الاراضي العراقية في مني لهي منطقة فيشخابور شمالا والى مدينة بغداد جنوبا (شكل 1). وبواقع 22 نموذجا خلال شتاء 2011 (جدول 1). ولغرض ملاحظة التغاير الموسمي في هيدروكيميائية النهر، فقد ثم اختبار 12 موقعا من المواقع السابقة لإعادة جمع النماذج خلال صيف 2011 (جدول 2). تم تحليل كل من العسرة الكلية (TH) والبيكربونات (وحسن، 1990). وتم تحليل النترات ( ${ }^{-}$(NO3 ${ }^{-}$باستخدام مطياف الاشعة فوق البنفسية وحسب الطريقة المذكورة

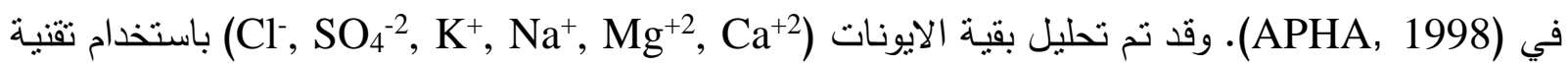
البلازمـا مزدوجـة الحث - قيـاس الطيف الكتلـي (ICP-MS). المستخدم في مختبرات شـركة اكسي في كندا

.(Acme Analytical Laboratories Ltd. Vancouver, Canada)

الجدول 1: نتائج تحليل الايونات الرئيسة الذائبة (0.45 م) في مياه نهر دجلة خلال فصل الثتاء (جميع

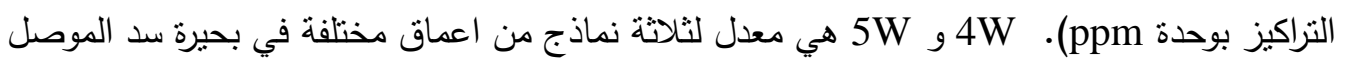

\begin{tabular}{|l|c|c|c|c|c|c|c|c|c|}
\hline $\begin{array}{l}\text { Elements } \\
\text { Sample }\end{array}$ & $\mathbf{C a}^{\mathbf{+ 2}}$ & $\mathbf{M g}^{\mathbf{+ 2}}$ & $\mathbf{N a}^{+}$ & $\mathbf{K}^{+}$ & $\mathbf{H C O}_{3}^{-}$ & $\mathbf{S O}_{4}^{-2}$ & $\mathbf{C l}^{-}$ & $\mathbf{N O}^{-}$ & $\mathbf{T H}$ \\
\hline 1M W & 79.14 & 24.87 & 15.14 & 2.43 & 239 & 96 & 9 & 0.72 & 300.2 \\
\hline 2M W & 78.1 & 24.69 & 14.86 & 2.27 & 239 & 87 & 13 & 0.72 & 296.9 \\
\hline 3M W & 69.73 & 24.57 & 15.12 & 2.56 & 231 & 90 & 14 & 0.71 & 296.9 \\
\hline 4 W (Average) & 70.78 & 21.38 & 16.8 & 2.38 & 212.37 & 88 & 10.7 & 0.6 & 275.4 \\
\hline 5 W (Average) & 65.39 & 19.68 & 13.53 & 2.16 & 191.93 & 89 & 9.3 & 0.26 & 275.4 \\
\hline 6M W & 64.66 & 18.92 & 12.01 & 2.05 & 195 & 84 & 8 & 0.25 & 239.5 \\
\hline 7M W & 67.25 & 20.24 & 14.62 & 2.5 & 200 & 84 & 9 & 0.25 & 251.4 \\
\hline 8M W & 68.64 & 19.96 & 13.48 & 2.57 & 200.1 & 93 & 8 & 0.22 & 253.7 \\
\hline 9M W & 73.25 & 22.13 & 16.99 & 2.44 & 206 & 105 & 12 & 0.21 & 274.2 \\
\hline 10M W & 75.33 & 23.21 & 18.66 & 2.54 & 208 & 114 & 13 & 0.21 & 283.8 \\
\hline 11M W & 76.19 & 23.04 & 19.75 & 2.73 & 213 & 120 & 14 & 0.32 & 285.3 \\
\hline 12M W & 76.46 & 22.59 & 20.83 & 3.15 & 215 & 117 & 15 & 0.34 & 284.1 \\
\hline 13M W & 76.75 & 21.65 & 17.87 & 2.85 & 219 & 102 & 13 & 0.49 & 281.0 \\
\hline 14M W & 80.43 & 22.77 & 18.15 & 2.32 & 229 & 102 & 14 & 0.51 & 294.8 \\
\hline 15M W & 82.43 & 23.27 & 20.22 & 2.55 & 248 & 99 & 14 & 0.55 & 301.8 \\
\hline 16M W & 83.31 & 23.75 & 20.61 & 3.06 & 249 & 102 & 15 & 0.52 & 306.0 \\
\hline 17M W & 82.96 & 23.75 & 19.52 & 2.24 & 246 & 102 & 15 & 0.54 & 305.1 \\
\hline 18M W & 84.32 & 23.21 & 22.19 & 2.81 & 248 & 105 & 16 & 0.55 & 306.3 \\
\hline 19M W & 84.75 & 24.7 & 21.92 & 2.51 & 248.9 & 114 & 17 & 0.59 & 313.5 \\
\hline 20M W & 79.02 & 22.29 & 18.74 & 2.15 & 257 & 81 & 13 & 0.43 & 289.3 \\
\hline 21M W & 82.69 & 27.24 & 32.69 & 4.15 & 260 & 147 & 25 & 0.28 & 318.8 \\
\hline 22M W & 171.58 & 48.3 & 105.61 & 3.95 & 298 & 469 & 81 & 0.3 & 627.7 \\
\hline Average & $\mathbf{8 0 . 6 0}$ & $\mathbf{2 3 . 9 2}$ & $\mathbf{2 2 . 2 4}$ & $\mathbf{2 . 6 5}$ & $\mathbf{2 2 9 . 7 0}$ & $\mathbf{1 1 7 . 7 3}$ & $\mathbf{1 6 . 2 7}$ & $\mathbf{0 . 4 4}$ & $\mathbf{3 0 2 . 8}$ \\
\hline
\end{tabular}


الجدول 2: نتائج تحليل الايونات الرئيسة الذائبة (0.45ر filtered) في مياه نهر دجلة خلال فصل الصبف (جميع

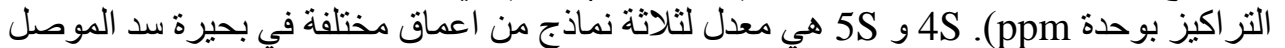

\begin{tabular}{|c|c|c|c|c|c|c|c|c|c|}
\hline $\begin{array}{l}\text { Elements } \\
\text { Sample }\end{array}$ & $\mathrm{Ca}^{+2}$ & $\mathrm{Mg}^{+2}$ & $\mathbf{N a}^{+}$ & $\mathbf{K}^{+}$ & $\mathrm{HCO}_{3}{ }^{-}$ & $\mathrm{SO}_{4}^{-2}$ & $\mathrm{Cl}^{-}$ & $\mathrm{NO}_{3}{ }^{-}$ & TH \\
\hline $1 \mathrm{M} \mathrm{S}$ & 60.51 & 16.92 & 11.53 & 1.81 & 194.00 & 54.00 & 12.00 & 0.40 & 220.90 \\
\hline $4 \mathrm{~S}$ ( Average) & 46.98 & 11.51 & 7.75 & 1.79 & 160.00 & 35.00 & 5.67 & 0.56 & 164.81 \\
\hline $5 \mathrm{~S}$ ( Average) & 48.96 & 13.06 & 10.00 & 1.99 & 162.67 & 48.00 & 7.67 & 0.29 & 176.14 \\
\hline $7 \mathrm{M} \mathrm{S}$ & 52.73 & 12.28 & 8.21 & 1.87 & 155.00 & 48.00 & 7.00 & 0.12 & 182.36 \\
\hline $8 \mathrm{M} \mathrm{S}$ & 52.77 & 12.59 & 8.98 & 1.85 & 155.00 & 51.00 & 7.00 & 0.16 & 183.74 \\
\hline 9M S & 55.09 & 12.70 & 9.92 & 1.83 & 157.00 & 54.00 & 9.00 & 0.22 & 189.99 \\
\hline 10M S & 58.30 & 13.15 & 10.78 & 1.93 & 165.00 & 57.00 & 11.00 & 0.32 & 199.87 \\
\hline 12M S & 56.35 & 13.82 & 11.95 & 2.11 & 160.00 & 63.00 & 11.00 & 0.28 & 197.75 \\
\hline 13M S & 53.74 & 14.83 & 12.14 & 1.99 & 159.00 & 72.00 & 12.00 & 0.35 & 195.38 \\
\hline 14M S & 57.25 & 14.80 & 12.82 & 2.02 & 167.00 & 69.00 & 12.00 & 0.37 & 204.03 \\
\hline 16M S & 56.65 & 14.95 & 12.33 & 1.83 & 165.00 & 66.00 & 12.00 & 0.42 & 203.15 \\
\hline 20M S & 56.91 & 15.35 & 16.68 & 2.12 & 164.00 & 81.00 & 18.00 & 0.46 & 205.44 \\
\hline Average & 54.69 & 13.83 & 11.09 & 1.93 & 163.64 & 58.17 & 10.36 & 0.33 & 193.63 \\
\hline
\end{tabular}

تم إدخـال بيانـات التحاليل الكيميائيـة للأيونـات الرئيسـة لميـاه نهر دجلـة (الجدولان 1،2) في البرنـامج الإحصـائي (SPSS). اذ تم اسـتخدام التحليـل العـاملي (Factor Analysis)، طريقـة المركبـات الاساسـية (Principal Component)، والتدوير (Varimax Rotation)، لتحديد العوامل المؤثرة على تراكيز الايونات. ويعد التحليل العاملي واحدا من التقنيات الاحصائية الثنائعة الاستخدام في التعامل مع البيانات الكيميائية لتحديد العلاقة بين عدد من المتغيرات في الوقت نفسه (Bakac and Kumru,2001)، وهو اسلوب احصائي يستهدف تلخيص العديد من المتغيرات لعدد أقل تعرف بالعوامل (Factors) بحيث ان كل مجموعة من المتغيرات ترتبط بشكل قوي مع عامل واحد فقط. ولغرض ملاحظة مدى الترابط بين النماذج المختلفة وامكانية تقسيم نماذج منطقة البحث الى مجاميع ثانوية تعبر عن مناطق محددة ضمن منطقة الدراسـة اعتمـادا على بيانات الايونات الرئيسـة، فقد تم استخدام التحليل العنقودي التراتبي (Hierarchical Cluster Analysis) طريقة (Word’s Method). الذي يعد أحد اهم التقنيات الاحصائية المستخدمة في مجال علوم الارض، والتي تساعد في تقسيم البيانات لعدد من المتغيرات الى مجاميع محددة. وتساعد في ترتيب النماذج بشكل مجاميع حقيقية. وتعرض النتائج بشكل مبسط حسب الثقارب بين النماذج ومجاميع النماذج (Danielsson et al.,1999; Chen et al., 2007). ومن اجل اعطاء اهمية متوازنة لجميع المتغيرات (Variables) في هذا التحليل (التحليل العنقودي) فقد تم اعتماد البيانات الخاصـة بقيم

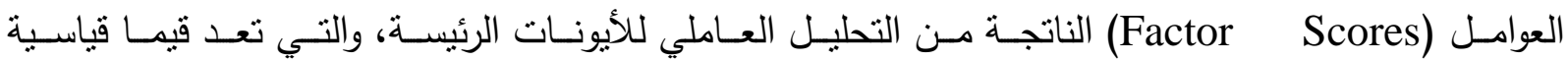
(Standardized) العملية الاحصائية بشكل اوضح وتكون المجاميع أكثر تمثيلا لواقع نماذج البحث الحالي، فقد تم استثناء نموذجي بحيرة سد الموصل من هذا التحليل على اعتبارهما معدلات لثلاثة نماذج من اعماق مختلفة وتتأثز بعوامل خاصـة

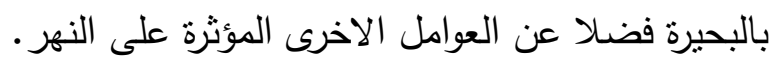




\section{التحليل الاحصائي والمناقشة}

تبين من خلال إجراء التحليل العاملي (Factor Analysis) لنماذج كل فصل على حدة، وجود عاملين رئيسين يؤثران على تراكيز الايونات الرئيسة خلال فصل الثتاء. ووجود ثناث عوامل مؤثرة على تراكيز الايونات

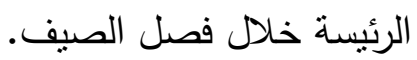


بعضها في خمسة عناقيد (Clusters) موزعة على طول منطقة الدراسة.

\section{التحليل العاملي لنماذج فصل الثتاء}

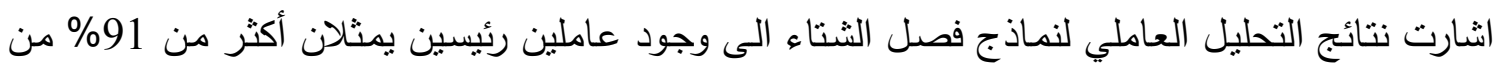
التباين (Variance). حيث يمثل العامل الأول 74.607\% من التباين بينما يمثل العامل الثاني 16.435\%؛

لاحظ الجدول (3).

الجدول 3: الحمل (loading) ومقدار التباين (Variance)و و)(Eigen values) و) للعامل الأول والثاني لنماذج فصل الثتاء

\begin{tabular}{|c|c|c|c|}
\hline Ions & Factor 1 & Factor 2 & Communalities \\
\hline $\mathrm{Ca}^{+2}$ & 0.976 & 0.103 & 0.963 \\
\hline $\mathrm{Mg}^{+2}$ & 0.979 & 0.126 & 0.974 \\
\hline $\mathrm{Na}^{+}$ & 0.991 & -0.049 & 0.984 \\
\hline $\mathrm{K}^{+}$ & 0.751 & -0.148 & 0.586 \\
\hline $\mathrm{HCO}_{3}^{-}$ & 0.746 & 0.559 & 0.868 \\
\hline $\mathrm{SO}_{4}^{-2}$ & 0.978 & -0.105 & 0.968 \\
\hline $\mathrm{Cl}^{-}$ & 0.991 & -0.015 & 0.983 \\
\hline $\mathrm{NO}_{3}{ }^{-}$ & -0.129 & 0.97 & 0.957 \\
\hline Eigen values & 5.981 & 1.303 & \\
\hline Variance(\%) & 74.607 & 16.435 & \\
\hline Cumulative(\%) & 74.607 & 91.042 & \\
\hline
\end{tabular}

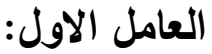

يشكل هذا العامل نسبة كبيرة من مجموع التباين (74.607\%) (الجدول 3)، وهو عامل أحادي القطب ويتمثل بالتحميل الموجب للمتغيرات التالية ( (2). ويمثل هذا العامل التجوية الكيميائية للمكونات الصخرية وعلى نطاق واسع في حوض نهر دجلة، حيث

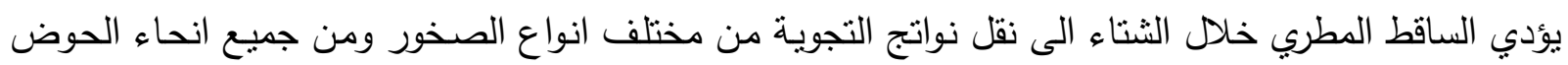
الى نهر دجلة، فضلا عن تأثثر تماس النهر مع مواد القعر . ان عملية نقل الحمولة الذائبة والمعلقة على نطاق التهاق

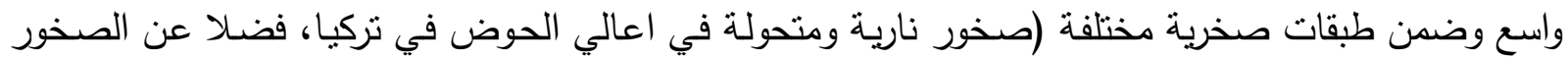

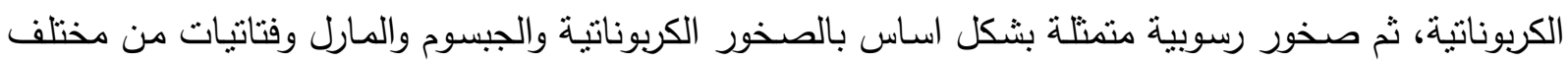

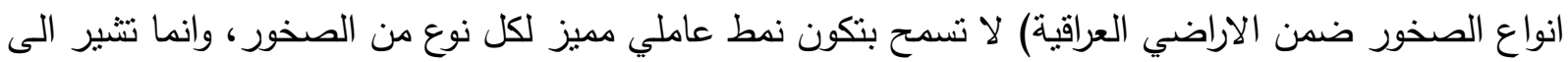

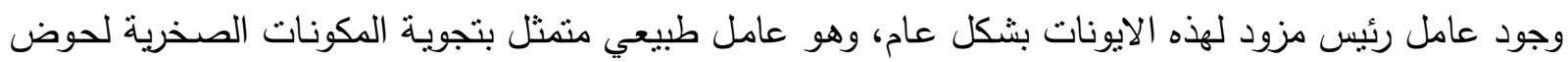


يثكل هذا العامل (16.435\%) مـن مجـوع التباين، ويعد ذا تأثنير محدود نسبة الـى العامل الاول، وينحصر تأثثره بشكل رئيس على التحميل الموجب لأيون النترات (الثكل 3)، وعليه فانه من المرجح ان يكون هذا العامل هو عامل غير طبيعي (Anthropogenic Factor) متمثل بما يطرح في النهر من فضـلات ومياه

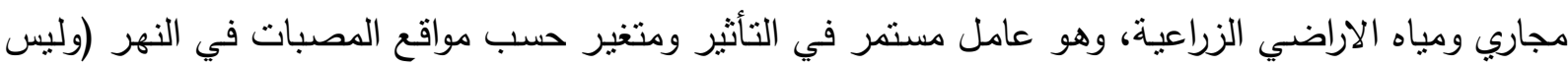
حسب التكوينات الجيولوجية).

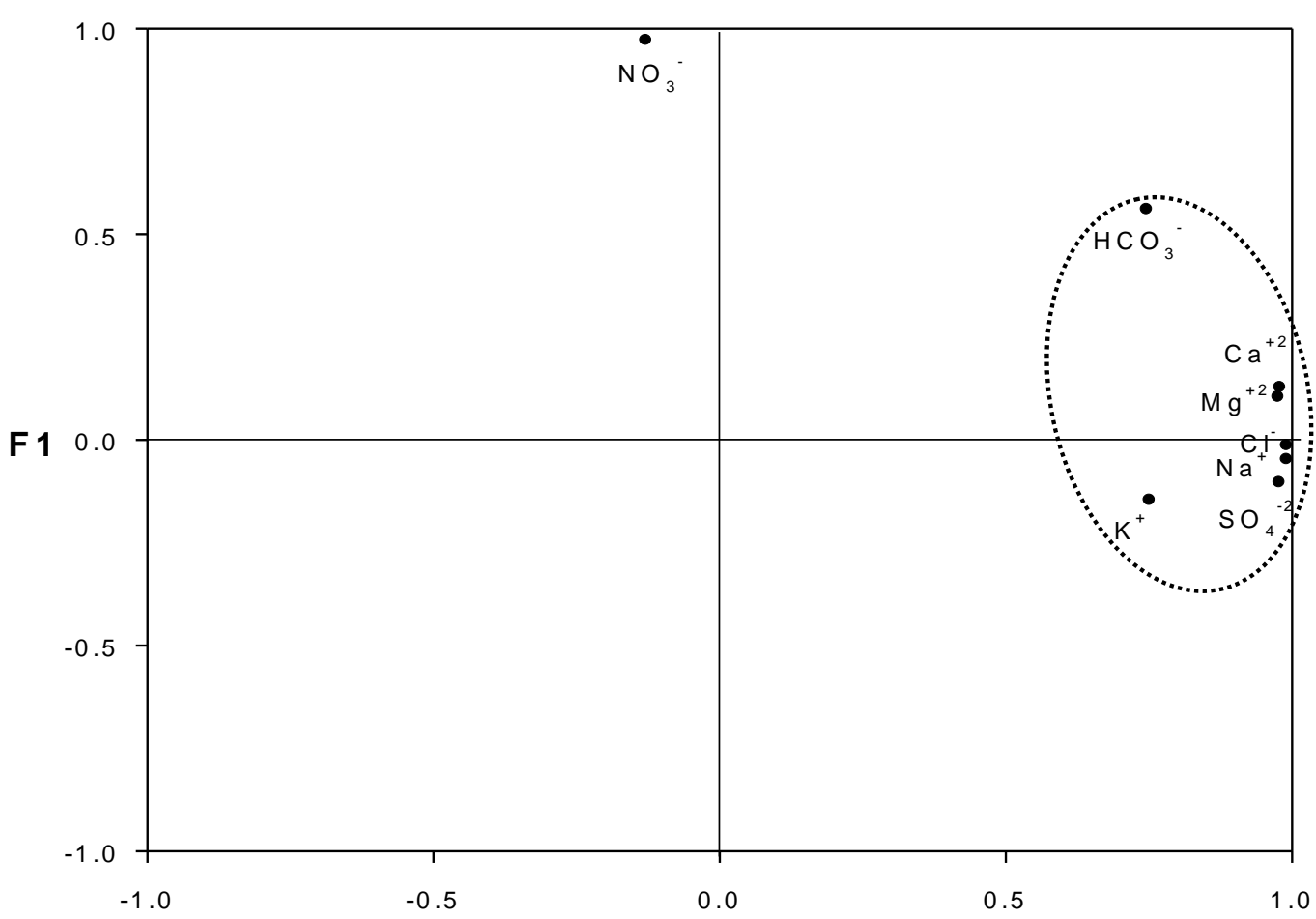

F 2

الثكل 2: مساقط نقاط العامل الأول والثاني لفصل الثناء

\section{التحليل العاملي لنماذج فصل الصيف}

تبين من التحليل العاملي لنماذج فصل الصيف ان هناك ثنلات عوامل رئيسة تمثل أكثر من 92\% من النباين (Variance). حيث يمثل العامل الأول 559.374\% من التناين، ويمثل العامل الثاني 20.654\%، بينما يمتل العامل الثنالث 12.659\% من التباين (الجدول 4).

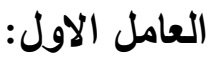

يشكل هذا العامل نسبة 59.374\% من مجموع التباين (الجدول 4)، وهو عامل أحادي القطب ويتمثل بالتحميل الموجب للأيونات (الثكل 3). ينضح من الايونات المحملة على هذا العامل انه بمثل التجوية الكيميائية لصخور المتبخرات، والتي تعود بشكل رئيس الى تكوين فتحة، حيث تمتد مكاشف صذور هذا التكوين على مساحات واسعة من حوض وقاع نهر دجلة. 


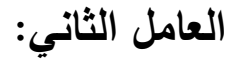

يشكل هذا العامل نسبة 20.656\% من مجموع التباين، وهو عامل أحادي القطب ويتمثل بالتحميل

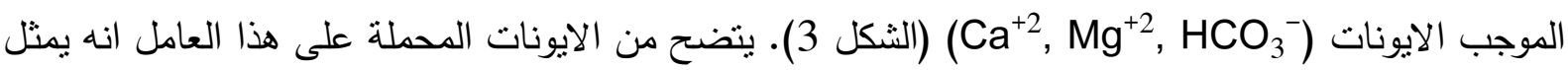
التجوية الكيميائية لصخور الكربونات، والتي تتكثف بشكل واسع ضمن المناطق العليا من حوض ومجرى النهر.

الجدول 4: الحمل (loading) ومقدار التباين (Variance) و و) و(Eigen values) و) للعامل الأول و الثاني و الثالث لنماذج فصل الصيف

\begin{tabular}{|c|c|c|c|c|}
\hline Ions & Factor 1 & Factor 2 & Factor 3 & Communalities \\
\hline $\mathrm{Ca}^{+2}$ & 0.39 & 0.842 & -0.214 & 0.918 \\
\hline $\mathrm{Mg}^{+2}$ & 0.447 & 0.824 & 0.217 & 0.916 \\
\hline $\mathrm{Na}^{+}$ & 0.884 & 0.376 & 0.239 & 0.952 \\
\hline $\mathrm{K}^{+}$ & 0.885 & -0.159 & -0.029 & 0.766 \\
\hline $\mathrm{HCO}^{-}$ & -0.136 & 0.884 & 0.342 & 0.927 \\
\hline $\mathrm{SO}_{4}^{-2}$ & 0.922 & 0.3 & -0.007 & 0.912 \\
\hline $\mathrm{Cl}^{-}$ & 0.827 & 0.482 & 0.217 & 0.966 \\
\hline $\mathrm{NO}_{3}^{-}$ & 0.124 & 0.13 & 0.97 & 0.967 \\
\hline Eigen values & 4.750 & 1.652 & 1.013 & \\
\hline Variance(\%) & 59.374 & 20.656 & 12.659 & \\
\hline Cumulative(\%) & 59.374 & 80.030 & 92.689 & \\
\hline
\end{tabular}

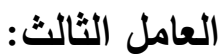

يثكل هذا العامل (12.659\%) من مجموع التباين، ويعد ذا تأثير محدود نسبة الى العاملين الاول

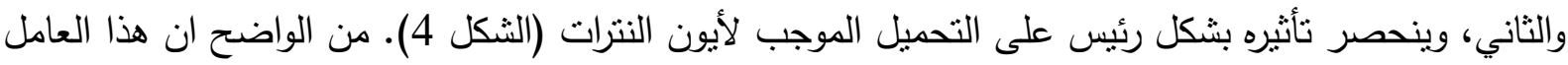

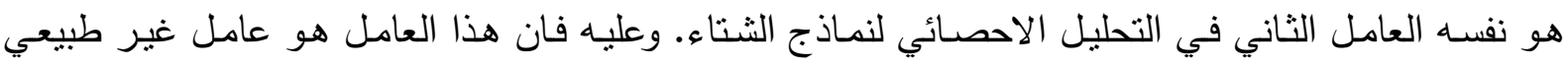
(Anthropogenic Factor)

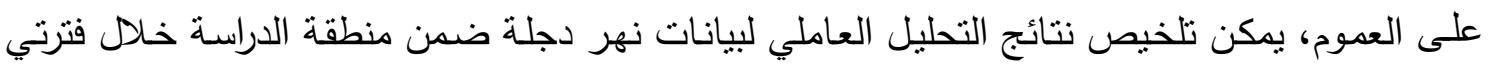
الندذجة، بان هناك عاملا رئيسا يتحكم بهيدروكيميائية العناصر الرئيسة في مياه النهر باستثناء النترات، وهذا لهاتيات

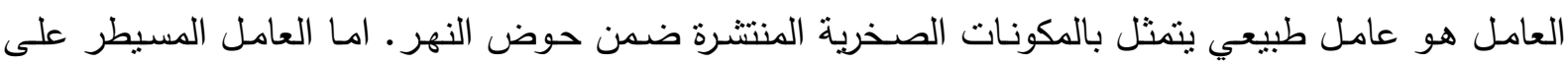
تراكيز النترات في منطقة الدراسة فهو عامل غير طبيعي يتمثل بما يطرح من فضلات في مياه النهر من المدن

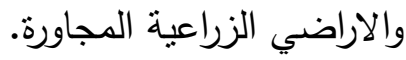



استخدام التحليل العاملي في تحديد العوامل المسؤولة عن تغاير تراكيز الايونات الرئيسة الذائبة.....

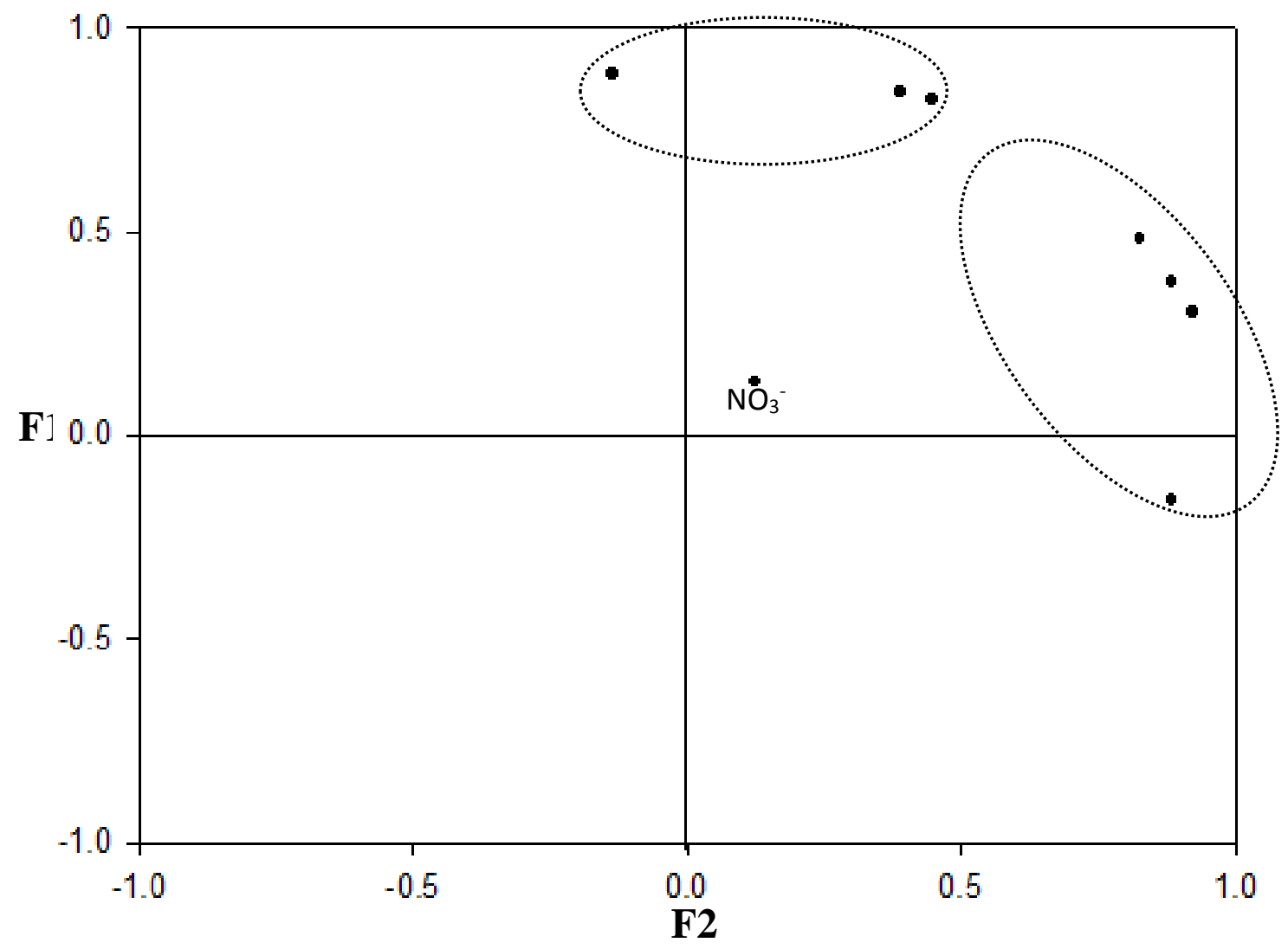

شكل 3: مساقط نقاط العامل الأول والثاني بعد التدوبر لنماذج فصل الصيف

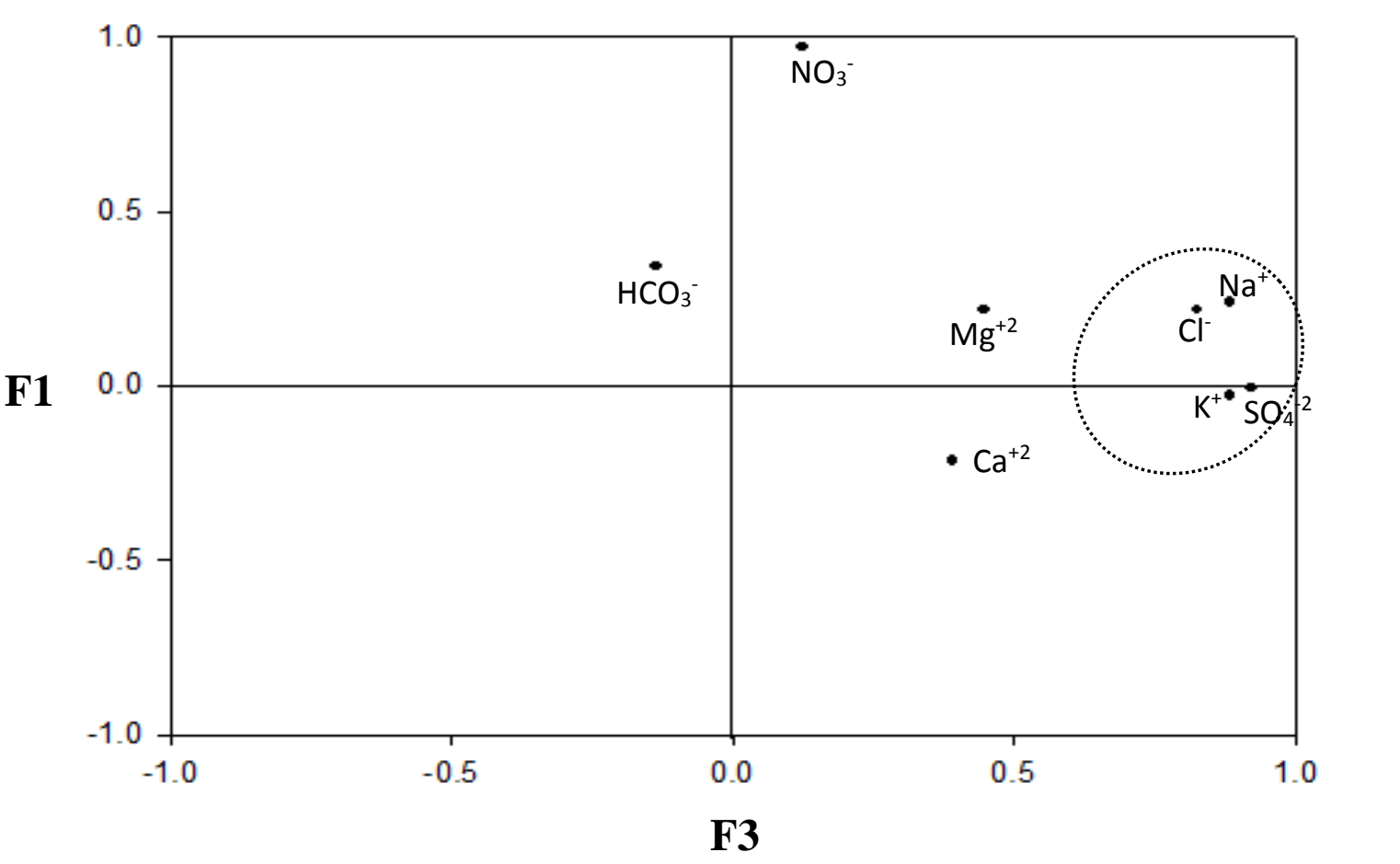

شكل 4: مساقط نقاط العامل الأول والثالث بعد التدوبر لنماذج فصل الصيف 


\section{التغاير في تراكيز الايونات الرئيسة}

يلاحظ من معدلات تراكيز الايونات الرئيسة في الجدولين (1 و2) ان هناك تغايرا موسميا في تراكيز الايونات الرئيسة، اذ تكون التراكيز خلال الثتاء اعلى منها خلال الصيف، وهذا يظهر بشكل واضح من تمثيل مجموع تراكيز الايونات لكل نموذج بوحدات الـ (epm) (الثكل 5). ومن المرجح ان هناك عددا من الاسباب وراء ازدياد التراكيز خلال الثتاء، ومن اهمها عمليات الغسل والاذابة، وهذا ايضا ما اشار اليه كل من (Al-Kattan, 1989; Rabee et al, 2011) في تفسيرهم لوجود زيادة نسبية للعناصر الثقبلة وكمية الاملاح الذائبة في مياه نهر دجلة خلال الثتاء نسبة الى الصيف ضمن مدينة الموصل ومدينة بغداد. كذللك زيادة عمليات تجوية الصخور في حوض النهر نتيجة لتساقط الامطار خلال الثتاء، ونقل نواتج التجوية الى النهر عن طريق الاودية والروافد الموسمية والدائمة. وهذا يتفق مع ما استتنجه اليوزبكي والبنا (2008) ; النعيمي (2010) من حيث وجود زيادة نسبية في نراكيز الايونات الرئيسة خلال الشتاء في عدد من الابار المحيطة بنهر دجلة. هذا فضلا عن زيادة تأثير عملية تغذية النهر من المياه الجوفية خلال موسم الامطار • خاصة وان كمية المياه المطلقة من سد الموصل الذي يعد واحدا من اقوى العوامل المتحكمة

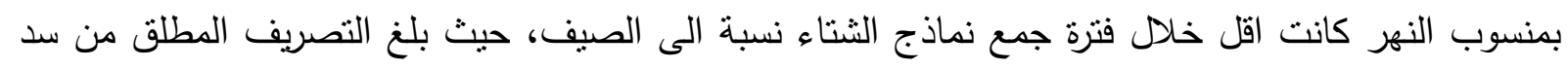

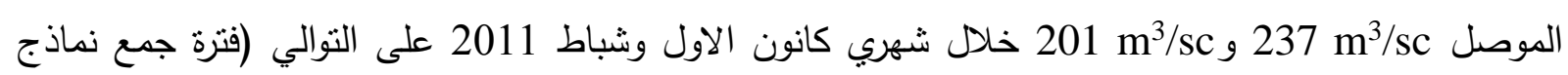

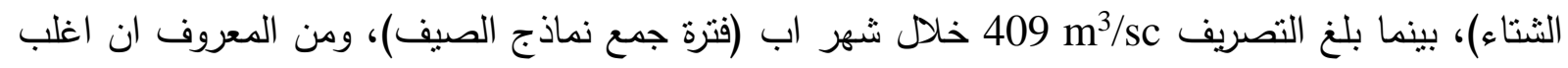
المياه الجوفية تكون ذات نراكيز ايونية اعلى من مياه الانهار. لئم

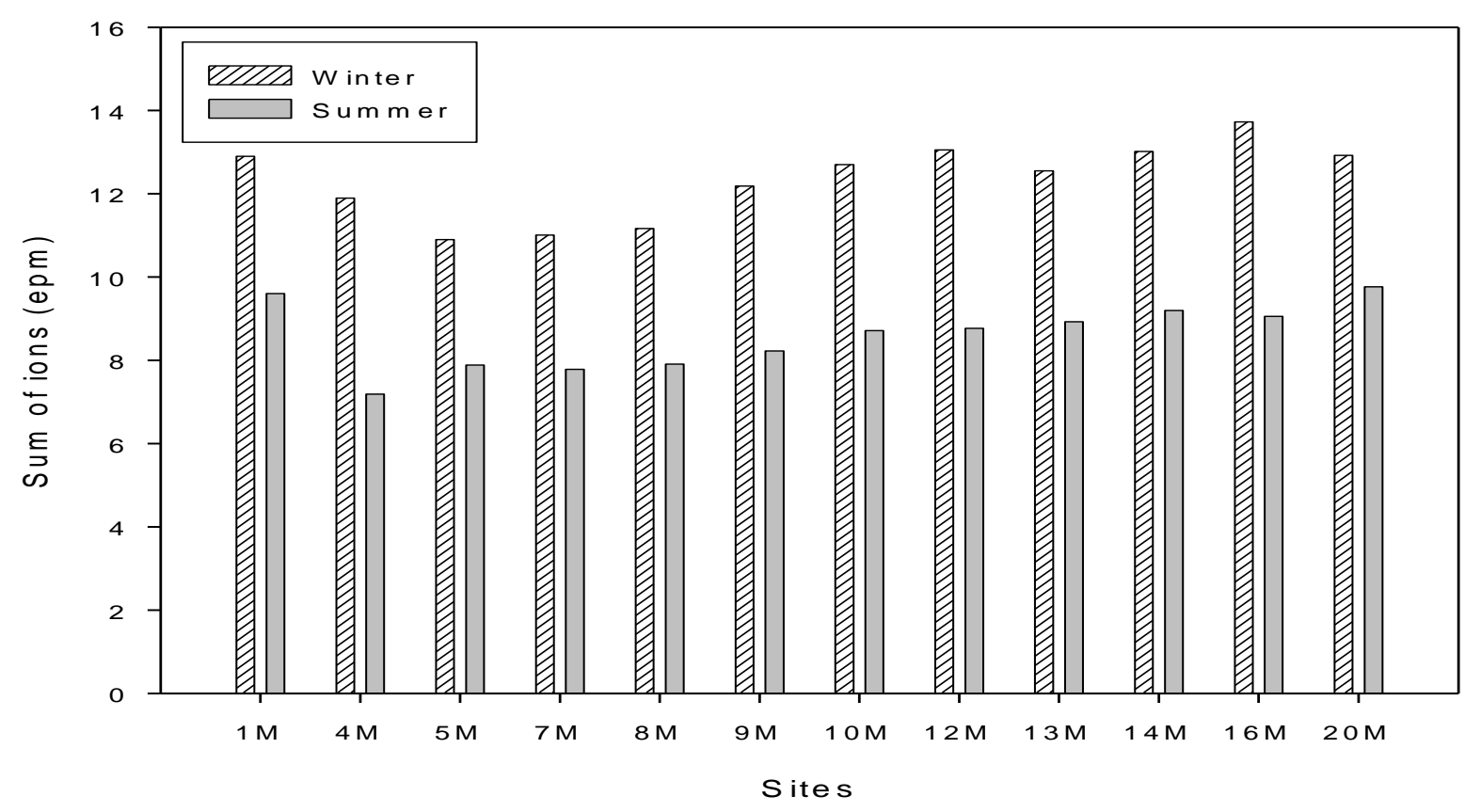

الثكل 3: مجموع الاوزان المكافئة (epm) للأيونات الرئيسة في مياه نهر دجلة ضمن منطقة الدر اسة، لموسمي الثتاء و الصيف لانف 
ومن اجل ملاحظة التغاير المكاني في تراكيز الايونات الرئيسة على طول منطقة الدراسة، وامكانية تقسيم منطقة الدراسة الى مجاميع ثانوية اعتمادا على هذا التغاير، فقد تم استخدام التحليل العنقودي.

التحليل العنقودي (Cluster Analysis)

اظهرت نتائج هذا التحليل انقسام نماذج كل فصل الى مجاميع ثانوية تحوي نماذج منقاربة في الخصائص الهيدروكيميائية. اذ يلاحظ تجمع نماذج منطقة البحث في خمسة مجاميع (ثكل 5). تبدا بالمنطقة الواقعة قبل وصول النهر الى بحيرة سد الموصل (النماذج,1MW,2MW, 3MW لفصل الثتاء، والنموذج 1 (MS خلال الصيف خلال الصيف). وتتميز هذه المنطقة بسيادة العسرة المؤقتة في مياه النهر والمتمثلة بوجود املاح البيكربونات الذائبة. نتيجة للتأثنير الرئيس لصخور الكربونات على هيدروكيميائية النهر ـ اما العنقود الثاني من بئه النماذج فتضم نماذج المنطقة المحصورة بين سد الموصل ومصب الزاب الاعلى في نهر دجلة خلال الثناء. اما خلال فصل الصيف فان هذه المنطقة نتتهي عند بداية مدينة الموصل (الثكل 5). في هذه المنطقة يبدأ تكوين فتحة بالتأثير على كيميائية النهر، حيث يقطع النهر التكوين في هذه المنطقة، وتزداد العسرة الدائمة في مياه النهر ، وهذا واضح خاصة في المنطقة الواقعة بين مدينة الموصل ومصب الزاب الاعلى. نتيجة لتأثنر صخور المتبخرات والعيون الكبرينية ومنطقة كبريت المشراق على تراكيز العناصر في مياه النهر ضمن هذه المنطقة. والمجموعة الثالثة من النماذج تعود الى نماذج المنطقة الممتدة بين مصب الزاب الاعلى والى جنوب قرية المسحك قبل ان يذخل النهر الى بيجي. في هذه المنطقة تتشارك املاح البيكربونات واملاح الكبريتات في التأثثر على كيميائية مياه النهر. وهذا نتيجة لتداخل تأثثر كل من صخور الكربونات المنكثفة بشكل واسع ضمن حوض الزاب الاعلى ونهر دجلة وصخور المنبخرات لتكوين فتحة ومنطقة العيون الكبرينية على نهر دجلة. ويلاحظ وجود تداخل للنموذجين 12MS و بين المنطقة الثانية والثالثة خلال فصل الصيف. وخلال سريان النهر باتجاه الجنوب يزداد تركيز الكبريتات والكلوريدات والصوديوم، بسبب زيادة الملوحة في ترب هذه المنطقة نتيجة لارتفاع درجات الحرارة وانخفاض الساقط المطري وارتفاع منسوب المياه الجوفية وزيادة ملوحتها كلما اتجهنا نحو الجنوب (الجواهري والثمري، 2009) الامر الذي ينسبب في عملية تملح التربة التي باتت من المشاكل البيئية في وسط وجنوب العراق (صالح، 2010). فضلا عن زيادة تأثير عمليات الغسل والاذابة وتراكمها بشكل ذائب في مياه النهر كلما زادت مسافة النقل، الامر الذي تسبب في انفصال نموذج منطقة الضلوعية (21M) عن المجموعة السابقة لبشكل مجموعة خاصة بهذه المنطقة. وبالاتجاه نحو مدينة بغداد تزداد تراكيز الايونات الرئيسة بشكل كبير وتزداد العسرة الدائمة في مياه النهر • اذ يلاحظ زيادة كبيرة في نراكيز الكبريتات والايونات الرئيسة المكونة لأملاح الكلوريدات (جدول 6). نتيجة لزيادة ملوحة التربة والتأثثر الكبير للمبازل ومياه مجاري الصرف الصحي لمدينة بغداد على مياه نهر دجلة (Rabee et al, 2011). وكذلك نتيجة لتأثير المياه القادمة من بحيرة الثرثار الى نهر دجلة والتي نكون ذات محتوى عالٍ من الكبريتات والكلوريدات والصوديوم، الامر الذي يؤدي الى ابتعاد نموذج مدينة بغداد (22M) عن بقية المجاميع بشكل واضح. ليشكل هذا النموذج منطقة خاصة به (شكل 5). 


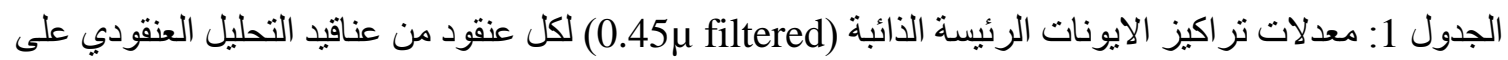
طول منطقة الدراسة في مياه نهر دجلة خلال فصلي الثنتاء و الصيف (جميع التر اكيز بوحدة (ppm).

\begin{tabular}{|c|c|c|c|c|c|c|c|c|c|}
\hline $\begin{array}{l}\text { Elements } \\
\text { Clusters }\end{array}$ & $\mathrm{Ca}^{+2}$ & $\mathrm{Mg}^{+2}$ & $\mathbf{N a}^{+}$ & $\mathbf{K}^{+}$ & $\mathrm{HCO}_{3}^{-}$ & $\mathrm{SO}_{4}^{-2}$ & $\mathrm{Cl}^{-}$ & $\mathrm{NO}_{3}^{-}$ & TH \\
\hline \multicolumn{10}{|c|}{ فصل الشتاء } \\
\hline 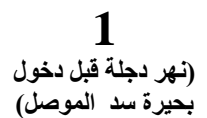 & 75.63 & 24.73 & 15.03 & 2.43 & 236.33 & 91.00 & 12.00 & 0.70 & 298.00 \\
\hline 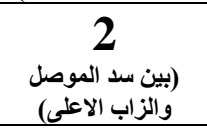 & 71.70 & 21.43 & 16.63 & 2.57 & 205.30 & 102.43 & 11.29 & 0.26 & 267.43 \\
\hline 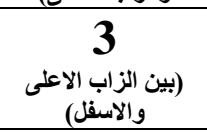 & 81.75 & 23.20 & 19.90 & 2.58 & 243.11 & 100.88 & 14.63 & 0.53 & 299.73 \\
\hline $\begin{array}{c}4 \\
\text { (منطقة الضلوعية) }\end{array}$ & 82.70 & 27.20 & 32.70 & 4.20 & 260.00 & 147.00 & 25.00 & 0.30 & 318.80 \\
\hline 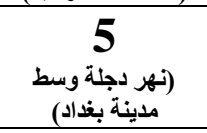 & 171.60 & 48.30 & 105.60 & 4.00 & 298.00 & 469.00 & 81.00 & 0.30 & 627.70 \\
\hline \multicolumn{10}{|c|}{ فصل الصيف } \\
\hline 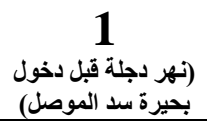 & 60.51 & 16.92 & 11.53 & 1.81 & 194.00 & 54.00 & 12.00 & 0.40 & 220.90 \\
\hline 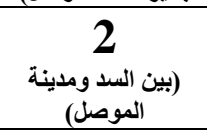 & 53.53 & 12.52 & 9.04 & 1.85 & 155.67 & 51.00 & 7.67 & 0.17 & 185.36 \\
\hline 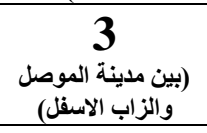 & 56.53 & 14.48 & 12.78 & 2.00 & 163.33 & 68.00 & 12.67 & 0.37 & 200.94 \\
\hline
\end{tabular}


استخدام التحليل العاملي في تحديد العوامل المسؤولة عن تغاير تراكيز الايونات الرئيسة الذائبة.......
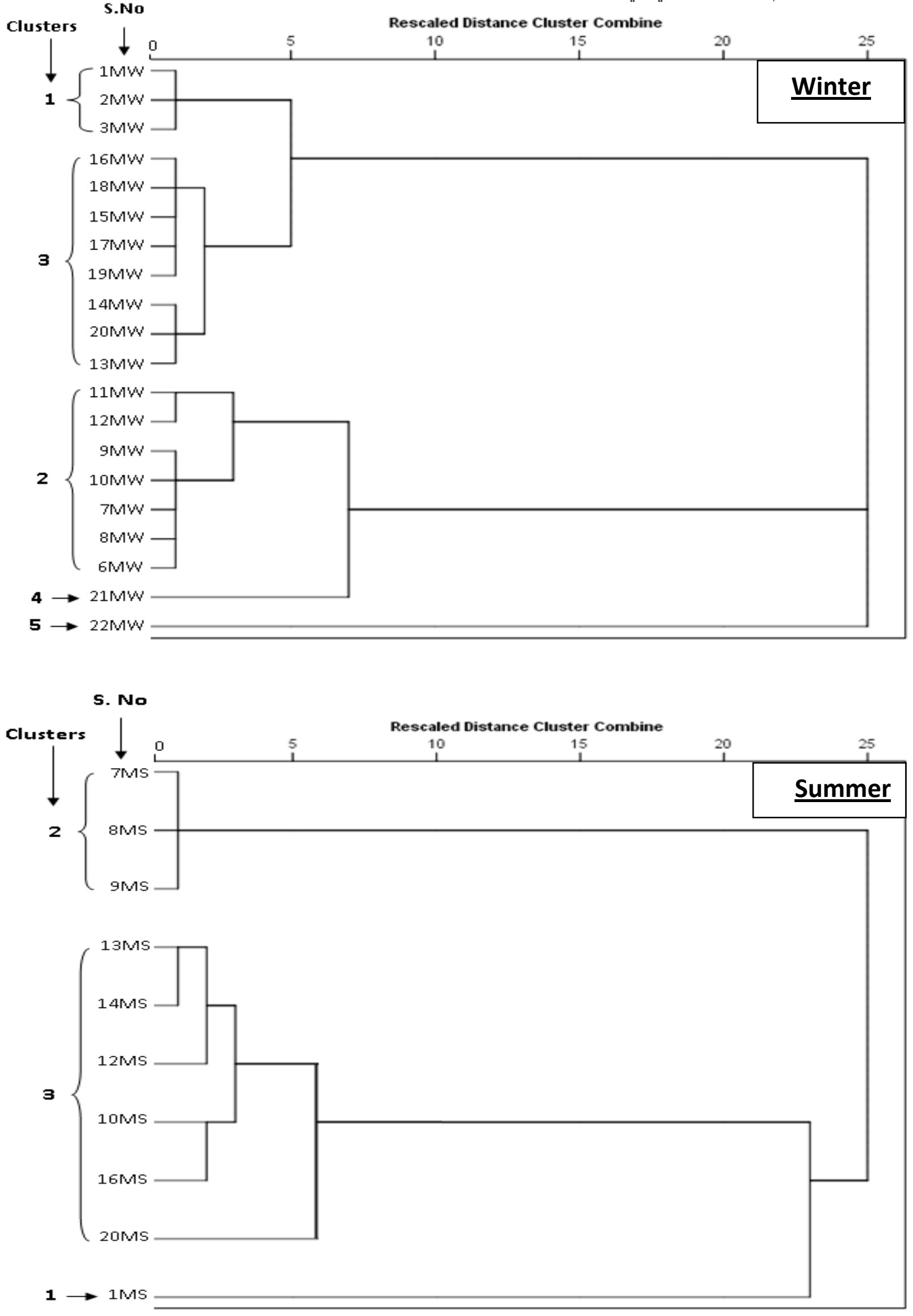

الثكل 5: المخطط الثجري للتحليل العنقودي التراتبي ( Dendrogram of the hierarchical cluster (analysis using the Ward method 


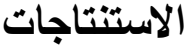

1- اظهرت نتائج التحليل العاملي للأيونات الرئيسة ان العامل الرئيس المتحكم بكيمياء مياه نهر دجلة هو نوعية الصخور المنتشرة ضمن حوض النهر • حيث تتشـارك كل من صخور الكربونـات والمتبخرات في التأثنر الاكبر على كيميائية نهر دجلة ضمن منطقة الدراسـة. ويلاحظ ايضـا وجود تأثنير محدود للعوامل غير الطبيعية التي ينحصر ثأثثرها على ايون النترات والتأثير قليلا على كل من الكلوريد والصوديوم. 2- تكون تراكيز الايونات الرئيسة في مياه نهر دجلة خـلال فصل الثتاء اعلى من تراكيزها خـلال الصيف، نتيجة لزيادة عمليات التعرية والتغذية من المياه الجوفية بفعل تساقط الامطار . 3- اشارت نتائج التحليل العنقودي الى تأثير العوامل الجيولوجية التي ساهمت في تقسيم نماذج كل فصل الى نى مجاميع ثانوية على طول مسار النهر نتيجة لتغاير تراكيز الأيونات الرئيسة على طول منطقة الدراسة.

\section{المصادر العربية}

البياتي، هشـام جاسم، 1980. هيدروكيميائية وجيوكيميائية نهر دجلـة والتلوث المحتمل من القيارة الى بغداد، رسالة ماجستير غير منشورة، كلية العلوم، جامعة بغداد، 211 صفحة. الجواهري، عمـاد احمد عبد الصـاحب، الثـمري، رضـا عبد الجبـار 2009. مشكلات المياه في العراق الواقع والحلول المقترحة، مجلة القادية للقانون والعلوم السياسية، العدد الاول، المجلد الثاني، ص 9-61. الخفاجي، جبار اللايج علي، 1985. دراسة الحمولة الذائبة في نهر دجلة داخل مدينة بغداد، رسالة ماجستير غير منشورة، كلية العلوم، جامعة بغداد، 182 صفحة. المرهج، زهير جاسم، 1979. هيدروكيميائية وجيوكيميائية والتلوث المحتمل لنهر دجلة، منطقة منجم كبريت المشراق، رسالة ماجستير غير منشورة، كلية العلوم، جامعة بغداد، 179 صفحة. صالح، وليد محمود، 2010. الاثار البيئية لتملح التربة (منطقة الدراسة ناحية اليوسفية) ، بحث مقدم للحصول على الدبلوم عالي، المعهد العالي للتخطبط الحضري والإقليمي للاراسات العليا، جامعة بغداد. عباوي، سعاد عبد وحسن، محمد سليمان، 1990ـ. الهندسة العملية للبيئة، فحوصـات الماء، دار الحرية للطباعة والنشر ، 296 صفحة.

النعيمي، حازم جمعة محمود، 2010. هيدروكيميائية ونوعية المياه لمجموعة من الآبار المنتشرة في منطقة وانة

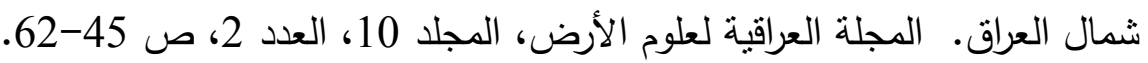
اليوزبكي، قتيبة توفيق والبنا، نبيل يوسف، 2008. التقييم النوعي للمياه الجوفية في آبار مختارة من منطقتي

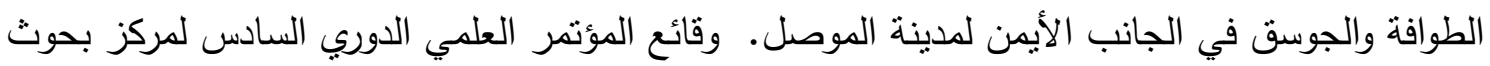
السدود والموارد المائية، جامعة الموصل، تشرين الأول، 2008. صفحة 91-103. 


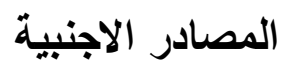

Adekola, F. A. and Eletta, O. A. A., 2007. A study of heavy metal pollution of Asa River, Ilorin. Nigeria; trace metal monitoring and geochemistry. Environ Monit Assess, Vol. 125, pp.157-163.

Al-Kattan, D. M. D., 1989. Trace element in Tigris River and their impact on drinking water. M. Sc. Thesis, College of Engineering, University of Mosul, 106 p.

APHA, 1998. Standard method for the examination of water and wastewater. 18th ed. APHA, AWWA WDGE, United States of America.

Anderson, R. R., Brown, R. G., and Rappleye, R. D., 1968. Water Quality and Plant Distribution along the Upper Patuxent River, Maryland. Chesapeake Science, Vol. 9, No. 3, pp. 145-156. Published on line by JSTOR.

Bakac, M and Kumru, M. N., 2001. Factor analysis in the geochemical studies along the Gediz River, Turkey. Journal of Radioanalytical and Nuclear Chemistry, Vol. 249, No. 3, pp. 617-624.

Chakrapani, G.J., 2005. Major and trace element geochemistry in upper Ganga River in the Himalaya, India. Environ. Geol. Vol.48, pp.189-201.

Chen, K. Jiu J. Jiao, J. J., Huang, J. and Huang, R., 2007. Multivariate statistical evaluation of trace elements in groundwater in a coastal area in Shenzhen, China. Environmental Pollution, Vol. 147 pp.771-780.

Danielsson, A., Cato, I., Carman, R., Rahm, L., 1999. Spatial clustering of metals in the sediments of the Skagerrak/Kattegat. Applied Geochemistry, Vol. 14, pp. 689-706.

Gaillardet, J., Viers, J. and Dupre, B., 2004. Trace element in river water. In: Holland, H.D. and Turekian, K.K. (Eds.). Treatise on Geochemistry, Surface and Ground Water, Weathering, and Soils, Elsevier Pergamon, Amsterdam, Vol. 5, pp. 225 272.

Ingri, J. Widerlund, A. and Land, M., 2005. Geochemistry of Major Elements in a Pristine Boreal River System; Hydrological Compartments and Flow Paths. Aquatic Geochemistry, Vol. 11, pp. 57-88.

Konhauser, K. O., Powell, M. A., Fyfe, W. S. Longstaffe, F. J. S. Tripathy., 1995. Trace element chemistry of major rivers in Orissa State, India. Environmental Geology, Vol. 29, pp. 132-141.

Kucuksezgin, F., Uluturhan, E., and Batki, H., 2008. Distribution of heavy metals in water, particulate matter and sediments of Gediz River (Eastern Aegean). Environmental Monitoring and Assessment, Vol.141, pp. 213-225.

Moskovchenko, D. V., Babushkin, A. G. and Artamonova, G. N., 2009. Surface water quality assessment of the Vatinsky Egan River catchment, West Siberia. Environ Monit Assess, Vol. 148, pp. 359-368.

Nicoll, K., 2009. Landscape development within a young collision zone: implications for post-Tethyan evolution of the Upper Tigris River system in southeastern Turkey. International Geology Review, Vol. 00, No. 0, pp. 1-19.

Pittaluga, M.A. and Suvires, G. M., 2006. Chemical Composition and Water Quality of the Castano River Calingasta, San Juan Province, Argentina. Multequina, Vol. 15 , pp. 17-26. 
Rabee, A. M., Abdul-Kareem, B. M. and Al-Dhamin, A. S., 2011. Seasonal Variations of Some Ecological Parameters in Tigris River Water at Baghdad Region, Iraq. Journal of Water Resource and Protection, Vol. 3, pp. 262-267.

Sabater, F., Sabater, S. \& Armengol, J., 1990. Chemical characteristics of a Mediterranean river as influenced by land use in the watershed. Water Research, Vol. 4(2), pp. 143-155.

Sanayei, Y., Ismail, N., \& Talebi, S. M., 2009. Determination of heavy metals in Zayandeh rood river, Isfahan- Iran. World Applied Sciences Journal, Vol. 6 pp. 1209-1214.

Scobee, E. R. and Prophet, C. W., 1967. Chemical Conditions in the Cottonwood River during the 1965 summer. Kansas Academy of Science, Vol. 70, No. 3, pp. 371-378. Published on line by JSTOR.

Souza, A. D. and Tundisi, J. G., 2000. HidroGeochemical Comparative Study of the Jau and Jacare-Guacu River Watersheds Sao Paulo, Brazil. Rev. Brasil. Biol., Vol. 60(4), pp. 563-570.

Sundary, S. K., Nayak, B. B., Kanungo, T. K. and Bhatta, D., 2012. Dynamics and quantification of dissolved heavy metals in the Mahanadi river estuarine system, India. Environ Monit Assess, Vol. 184, pp.1157-1179. 